\title{
Behavioral Intention to Use Public Transport Based on Theory of Planned Behavior
}

\author{
Kamarudin Ambak $^{1, a}$, Kanesh Kumar Kasvar ${ }^{1}$, Basil David Daniel ${ }^{1}$, Joewono Prasetijo ${ }^{1}$ and Ahmad \\ Raqib Abd Ghani ${ }^{1}$ \\ ${ }^{1}$ Smart Driving Research Center, Universiti Tun Hussein Onn Malaysia, 86400 Batu Pahat, Johor, Malaysia
}

\begin{abstract}
An increase in population generates increasing in travel demand. In Malaysia, public transport become an important modes of transport that connection people. This paper presents behavioural intention to use public transport especially public bus based on Theory of Planned Behaviour (TPB). A questionnaire survey was conducted to identify factors that contribute and influence users to use public bus and to determine factor that most dominant using TPB model. A total of 282 questionnaires were distributed in selected area of Batu Pahat and Kluang. Correlation and regression analysis were used for this study. Results show that the Attitude toward public transport is the most dominant factor compared with Subjective Norm and Perceived Behavior Control that influencing users to use public bus. Majority respondents were agreed that they prefer to use public bus because it is cheap to travel and no other choices of other transfer modes. As for the recommendation, this study can be extended in future as part of strategic sustainable transportation system in Batu Pahat and Kluang areas.
\end{abstract}

\section{Introduction}

Malaysia is one of the substantial developing nations in South East Asia. Transportation plays vital role in Malaysia economic contribution. Modern day busy lifestyles have increased the value of time. Public transport interpreted as a shared passenger transport service that is applicable for public uses as the movement of people and good to meet the basic need of society that require mobility and access [1]. Rapid population growth and economic growth have been able to embark on extension and improvement of the current transportation system. Malaysia's population growth has been on a downward trend over the past 10 years in line with other urbanizing countries [2]. There are four type modes of public transport such as highway, railway, airway and water. The most common types of public transport that are widely used in Malaysia are buses, airlines, taxis, trains and rails. On the other hand, public transport in Malaysia becomes a very important travel mode on a daily basis in human society. The modes of public transport system that exist in the study areas are land transportation modes such as public buses and taxis. Numbers of people using route F050, Jalan Batu Pahat to Kluang rapidly growing due to the establishment of higher education institution and manufacturing factories [4]. The important of public transport necessary in the study area due to increase in demand.

\footnotetext{
${ }^{a}$ Corresponding author : kamardin@uthm.edu.my
} 
Generally, demand of public transportation increased rapidly from year to year. Mainly in urban areas, public transportation has become necessary for their lifestyle due to traffic congestion issues and more environments. Malaysian government highly recommends public to utilize public transport in order to decrease traffic flow, reduce accident rate and also initiative for more savings due to increase of fuel prices [19]. Here in Batu Pahat and Kluang area, most widely public transportation has become mobility and access for people to travel from one place to another place. Mostly, public here at the Batu Pahat and Kluang area, use public transport on a daily basis such as travel from home to school, workplace and also college or university. There are also most people using public transport to go bus stand and also purchase of groceries from the supermarket. Besides that, there are few people who prefer public transport as mode of transport as travelling to the malls for movies and shopping. Transportation quality is acknowledged to consist two parts: the objective aspect, such as performance measures and service measure such as how customer perceives the service [1, 2]. These two aspects are significant in influencing intention user to use public bus.

Therefore, this study are to identify factors that contribute and influence users to use public transport at Batu Pahat and Kluang area and to determine factor that most dominant based on Theory of Planned Behaviour (TPB). This study was conducted on public transport especially feeder buses at routes along Batu Pahat to Kluang such as Johore Motor and Causeway Link bus companies. This two bus service company had been major bus companies involved in stage buses along these routes for several years. Moreover, this study was conducted randomized in Batu Pahat and Kluang bus station. The chosen travel route is route F050 Jalan Batu Pahat to Kluang.

\section{Theory of Planned Behaviour}

The theory proposes a model which can measure how human actions are guided. It predicts the occurrence of a particular behaviour, provided that behaviour is intentional. The theory of planned behaviour (TPB) in Figure 1 was developed by Icek Ajzen in 1985 [5]. The theory of planned behaviour is an extension of the theory of reasoned action [6]. The model is out lined in the next figure and represents the three variables which the theory suggests will predict the intention to perform behaviour. The intentions are the precursors of behaviour. There are three main components of TPB namely subjective norms, attitude and perceived behavioural control.

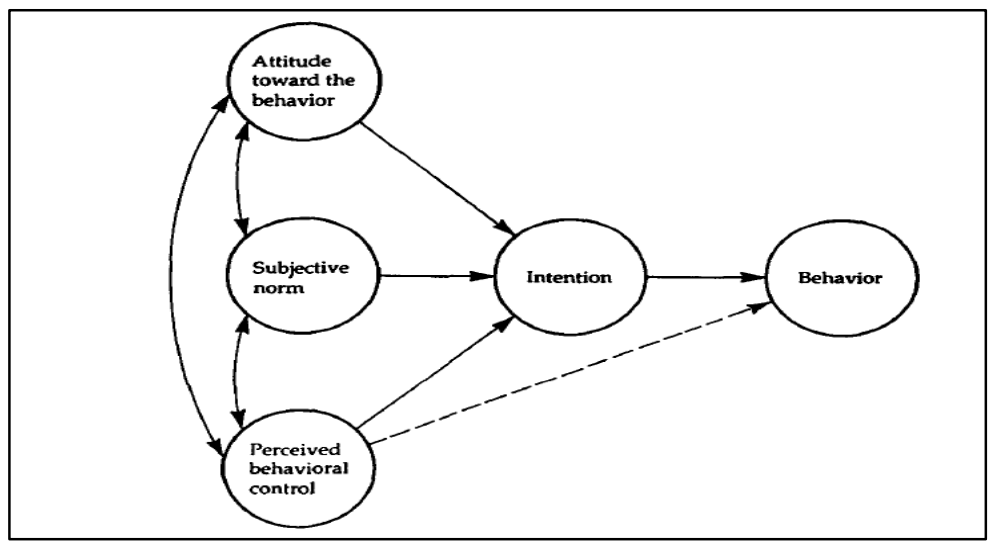

Figure 1. Theory of planned behaviour [5].

There are many studies that used TPB as model to study behaviour. The TPB has been applied successfully to predict and explain diverse behaviours, such as voting choices, weight loss, smoking cessation, social sciences, transportation and committing traffic violations [7, 18]. The effectiveness of U-pass programs has been examined in Canada using [8] TPB model and reduced car use among university students is generally found. A study by Wen and Ching [9] on Kaohsiung Mass Rapid Transit System, Taiwan shows public transit passengers' behaviours by constructing a comprehensive 
model considering public transit involvement, service quality, perceived value, satisfaction, and behavioural intentions at Taiwan,). In Vietnam, a study on the behavioural intention to use the bus while considering the perceived quality of bus service, problem awareness, and moral obligation [10]. Also, others related to traffic safety focus on motorcycle and helmet use in Malaysia [17].

\section{Materials and Methods}

This study chooses the questionnaire as research tool. Questionnaire developed based on Theory of Planned Behaviour (TPB). This questionnaire is divided into three parts, first part is the respondent's demographic analysis or information of the respondents, the second part is about perceived quality of public bus services and the third part is intention to use public bus based on Theory of Planned Behaviour (TPB). The five-point Likert scale used for the study and respondents answered the questions by lowest point as 1 (totally disagreed) and highest point as 5 (totally agreed).

The location of study that was determined at route F050, along Jalan Batu Pahat to Kluang. This route selected because the demand of public bus in this area are increasing due to rapid development of housing estate and office-shop building, also surrounded by educational institutes and factories. A pilot study of a total 20 respondents among public bus users were chosen to answer the questionnaire that was developed. Cronbach Alpha scores are used as a reference for analyzing the reliability of internal consistency questionnaire items. Cronbach alpha reliability coefficient that indicates the items connected to each other. The reliability of the questionnaire in the pilot study is to obtain Alpha value of 0.6 and above [12].

The questionnaires were distributed in selected bus terminal and bus stops along Jalan Batu Pahat and Kluang road. Respondents were randomly selected in term of gender, age, race, education level, purpose of using public bus and frequency of using public bus in a week. Respondents must be Malaysian citizens because the questionnaires were designed in "Bahasa Malaysia". According to [13] suggested that a minimum sample size of 200 is appropriate for any multivariate statistical analysis thus for this study total 282 respondents were chosen. The findings were analyzed using Statistical Package For Social Science (SPSS) version 22.0. Descriptive statistics, correlation and regression analysis were conducted to achieve study objectives and to determine relationship between variables.

\section{Results and Discussion}

Table 1 shows the descriptive analysis about respondent gender, age, level of education, occupation, race, income per month, and purpose of using public bus and frequent of using public bus per week. The descriptive statistics analysis and the findings shows that most of the public bus users are female ager ranged 20-30 years. It also shows that respondents were still pursuing in college or university and income less than RM1000.00. Meanwhile, most of respondents that using public bus was Malay. According to [14] majority populations in Batu Pahat and Kluang area were Malay. It is clear that, Batu Pahat and Kluang area is strategic location with many education institute established here. This shows public bus users mostly are students with less income and age not exceed 30 years. The study also shows education is main purpose of using public bus and frequency using public bus was 1 to 5 times per week.

Table 2 shows mean scores and standard deviations on quality of public bus services generally. Respondent's give their feeback on several aspects such as comfort, convenience, speed, punctuality, security, staff services, sufficient of seating places, cleanliness and breakdown experience. The respondents were influenced to use public bus because it is cheap to travel and cost-saving compare to private vehicles. Comprehensive improvements, such as Bus Rapid Transit systems, can provide large increases in transit use and attract large numbers of discretionary riders who would otherwise travel by automobile [14]. 
Table 1. Descriptive statistics.

\begin{tabular}{llcc}
\hline \multirow{2}{*}{ Gender } & Item & Frequency & $\begin{array}{c}\text { Percentage } \\
(\mathbf{\%})\end{array}$ \\
\hline \multirow{4}{*}{ Age } & Male & 129 & 45.7 \\
& Female & 153 & 54.3 \\
& Less Than 20 & 31 & 11.0 \\
& Years & 241 & 85.5 \\
20-30 Years & 8 & 2.8 \\
30-40 Years & 2 & .7 \\
Education Level & 40 Years and & & \\
& Above & 2 & .7 \\
Income & Primary School & 26 & 9.2 \\
& Secondary School & 99 & 35.1 \\
& Diploma/STPM & 154 & 54.6 \\
& Graduate & 45 & 69.9 \\
Purpose of Using & Less Than 1000 & 31 & 16.0 \\
Public Bus & 10001-2000 & 9 & 11.0 \\
& 2001-3000 & 27 & 3.2 \\
& 3001 and Above & & \\
Frequency of Using & Work & 45 & 9.6 \\
Public Bus & Daily Routine & 143 & 16.0 \\
& Education & 60 & 50.7 \\
& Entertainment & 7 & 21.3 \\
& 1-5 times & 137 & 48.6 \\
& 6-10 times & 73 & 25.9 \\
& More than 11 & 72 & 25.5 \\
& times & & \\
\hline
\end{tabular}

Table 2. Mean score and standard deviation for quality of public bus services.

\begin{tabular}{lcc}
\hline \multicolumn{1}{c}{ Item } & Mean & Std. Deviation \\
\hline Comfort of using public bus. & 2.85 & .79 \\
Usage of public bus facilitates users. & 3.41 & .86 \\
Bus driver obey to speed limit and drive with prudence. & 2.90 & .84 \\
Public bus adheres of time punctuality. & 2.46 & .87 \\
On-board security level when travelling in public bus. & 2.89 & .83 \\
Level of services provided by bus driver and conductor is satisfactory. & 3.21 & .81 \\
Adequacy of seating place in public bus. & 2.81 & .91 \\
Cleanliness in public bus is satisfactory & 2.65 & .85 \\
Experienced breakdown when travelling in public bus. & 1.76 & .44 \\
\hline
\end{tabular}

From Table 3, there was a moderately positive relationship between intention and behavior with $\mathrm{r}=0.527$ and $\mathrm{p}<0.01$. While, attitude, subjective norm, perceived behavioral control and behavior demonstrate a weak positive relationship with $r=0.272,0.223,0.270$ and $p<0.01$. It means all components in TPB are found significantly contribute to behavior intention to use public bus. The relationship between intention and behaviour shows high significant value, but the main three components that focused on are attitude, subjective norms and perceived behavioural control. Similar to Health \& Gifford [15] found that intention is strongly associated with behaviour compared with attitude linked with intention. Ambak et al. [16] were found a significant positive correlations with intentions and behavior toward helmet usage. 
Table 3. Correlation analysis for TPB components.

\begin{tabular}{lccccc}
\hline & ATT & SN & PBC & INT & BEH \\
\hline ATT & 1 & & & & \\
SN & $.291^{* *}$ & 1 & & & \\
PBC & $.464^{* *}$ & $.253^{* *}$ & 1 & & \\
INT & $.460^{* *}$ & $.197^{* *}$ & $.364^{* *}$ & 1 & \\
BEH & $.272^{* *}$ & $.223^{* *}$ & $.270^{* *}$ & $.527^{* *}$ & 1 \\
\hline
\end{tabular}

Notes**: Correlation is significant at the 0.01 level (2-tailed)

$\mathrm{INT}=$ Intention, ATT=Attitude, $\mathrm{PBC}=$ Perceived Behavioural Control,

$\mathrm{SN}=$ Subjective Norms, $\mathrm{BEH}=$ Behaviour

There are two level regression analyses were conducted from TPB model. Firstly, multiple regression analyses were conducted to examine the relationship between Intention and Attitude, Subjective Norms (SN) and Perceived Behavioural Control (PBC). Secondly, simple regression analysis was performed between Behaviour and Intention variables. Table 4 presents the coefficients value of Attitude, Subjective Norm and Perceived Behavioral Control on multiple regression analysis. Attitude and Perceived Behavioral Control components show the strong relationship $\left(\beta_{1}=0.239\right.$ and $\left.\beta_{2}=0148, \mathrm{p}<0.05\right)$ with Intention. There are some studies show a relatively strong relationship between attitudes and behavioural intentions $[15,18]$.

Table 4. Coefficients of regression on attitude, subjective norm and perceived behavioural.

\begin{tabular}{lrrrrr}
\hline \multicolumn{5}{c}{ Coefficients } \\
\hline \multicolumn{7}{c}{ Unstandardized Coefficients } & Standardized Coefficients & & \\
Model & B & Std. Error & Beta & \multicolumn{1}{c}{ S } & Sig. \\
1 (Constant) & 1.388 & .641 & & 2.166 & .031 \\
ATT & .239 & .040 & .361 & 5.992 & .000 \\
SN & .043 & .053 & .044 & .806 & .421 \\
PBC & .148 & .047 & .186 & 3.127 & .002 \\
\hline
\end{tabular}

a. Dependent Variable: Intention

Table 5 shows result on simple linear regression analysis. There is a strong relationship between Intention $(\beta=0.441, p<0.001)$ and Behaviour variable in TPB model. In addition, the analysis shows that the coefficients of determination, $\mathrm{R}^{2}=0.527$, which means $52.7 \%$ of variance in Intention can be explained in Behavior. A study [15] found that intention is strongly associated with behaviour compared with attitude linked with intention. Contrary with Sumaerdi et al. [17] mentiod that service quality and perceived value have direct and positive effect on behavior intention.

Table 5. Coefficients of regression on intention.

\begin{tabular}{|c|c|c|c|c|c|c|}
\hline \multicolumn{7}{|c|}{ Coefficients } \\
\hline & Unstandardi & d Coefficients & Standardized Co & ients & & \\
\hline \multirow{3}{*}{$\begin{array}{l}\text { Model } \\
1 \text { (Constant) } \\
\text { INTENTION }\end{array}$} & B & Std. Error & Beta & & $\mathrm{t}$ & Sig. \\
\hline & 3.694 & .275 & & & 13.413 & .000 \\
\hline & .441 & .042 & & .527 & 10.387 & .000 \\
\hline
\end{tabular}

a. Dependent Variable: Behaviour

\section{Conclusion}

The modes of public transport system that exist in the study areas are land transportation modes such as public buses and taxis. This study is focused on the behavioral intention to use public bus using the Theory of Planned Behavior (TPB). Descriptive statistics analysis of demographic, and experience, 
mean score and standard deviation are used to determine perceived quality of bus services The highest mean score that contributes and influence users to use public transport at Batu Pahat and Kluang area to use a public bus is factor on cheaper than private transportation. While, the lowest mean score that identified is factor on the use of public bus may reduce traffic congestion. Correlation and regression analysis were used to analysis TPB components. The results show that three significant factors in TPB that influence public bus user to use bus are Attitude, Perceived Behavioral Control and Intention. Factors that influence public bus user to use public bus are public bus cheap to travel and no choices of travel modes. It can be concluded that positive attitude toward saving cost and having no other travel modes will encourage public transport (bus) ridership.

\section{Acknowledgment}

The authors would like to thanks Universiti Tun Hussein Onn Malaysia (UTHM) for funding this study under the CoR Contract Research Grant Vot U395 and Smart Driving Research Center (SDRC), Faculty of Civil and Environmental Engineering for support and providing facilities to accomplish the study.

\section{References}

[1] L.A. Hoel and A.W. Sadek. Transportation Infrastructure Engineering: A Multimodal Integration, Cengage Learning, (2011).

[2] M.M. Rohani, D.C. Wijeyesekera and A.T.A. Karim, Bus operation, quality service and the role of bus provider and driver, Procedia Engineering, 53,167-178, (2013).

[3] Land Public Transport Commission Malaysia, Annual Report, 1, 26-27, (2012).

[4] A.A.S. Mohamad, Study towards service quality for Johore Motor bus at routes from Batu Pahat to Ayer Hitam, BEng Thesis, UniverstitiTun Hussein Onn Malaysia, Johor, (2007).

[5] I. Ajzen, From intentions to actions: A theory of planned Behaviour, In J. Kuhl and J.Beckmann (Eds.), Action-Control: From cognition to Behaviour, 11-39, (1985).

[6] I. Ajzen and M. Fishbein, Understanding attitudes and predicting social behaviour, Journal of Experimental Social Psychology, 45-76, (1980).

[7] I. Ajzen, Organizational behaviour and human decision processes, University of Massachusetts, (1991).

[8] J. Brown, D. Hess and D. Shoup, Unlimited access. Paper presented at the Conference of the Transit and University Communities, (1998).

[9] T.L. Wen and C.C. Fu, Behavioural intentions of public transit passengers: The roles of service quality, perceived value, satisfaction andInvolvement, Transport Policy Patent 18, 318-325, (2011),

[10]F. Satoshi and T.V. Hong, Psychological determinants of the intention to use bus in Ho Chi Minh City, Journal of Public Transportation, 12, 1, (2009).

[11]A. Doug, Statistics in medicine, MRC Clinical Research Centre, Watford Road, United Kingdom, 1, 59-71, (2006).

[12]J. Gliem and R. Gliem, Calculating, Interpreting, and reporting cronbach's alpha reliability coefficient for likert-type scales, Midwest Research to Practice Conference in Adult, Continuing, and Community Education, (2003).

[13]R. Weston and P.A. Gore, A brief guide to structural equation modeling, The Counseling Psychologist, 34(5), 719 - 751, (2006).

[14]Nelson, Primitivo, Hussein and E. Crispin, An assesment of the van for hire as a local public transport mode in Bohol, Phillipines, University of the Philippines, (2005).

[15] Y. Heath and R. Gifford, Extending the theory of planned behaviour: predicting the use of public transportation, Journal of Applied Social Psychology, 30-78, (2002). 
[16]K. Ambak, R. Ismail, R.A. Abdullah and M.N. Borhan, Prediction of helmet use among malaysian motorcyclist using structural equation modeling, Australian Journal of Basic and Applied Sciences 4(10), 5263-5270, (2010).

[17]S. Sumaedi, G.M.Y. Bakti and M. Yarmen, The empirical study of public transport passengers' behavioral intentions: The roles of service quality, perceived sacrifice, perceived value, and satisfaction (Case study: Paratransit passengers in Jakarta, Indonesia), International Journal for Traffic and Transport Engineering, 2(1), 83 - 97, (2012).

[18] M.B. Ahmed, K. Ambak, A. Raqib and N.S. Sukor, Helmet usage among adolescents in rural road from the extended theory of planned behaviour, Journal of Applied Sciences, 13, 161-166, (2013).

[19]R. Ismail, M.H. Hafezi, R. Mohd Nor and K. Ambak, Passengers preference and satisfaction of public transport in Malaysia, Australian Journal of Basic and Applied Sciences, 6(8), 410-416, (2012). 